\section{Recordando el Síndrome de Reye en tiempos de COVID-19}

\section{Remembering Reye's Syndrome in times of COVID-19}

\section{Sr. Editor:}

El mundo se enfrenta a una crisis debido a la actual pandemia causada por el SARS-CoV-2, un virus de cadena simple de ARN que causa la enfermedad denominada "Coronavirus Disease 2019" (COVID-19) ${ }^{1}$. El primer caso de este virus se reportó a fines de diciembre del 2019 en Wuhan, China y hasta el 20 de septiembre ya se habían reportado más de 30,6 millones de casos y 950.000 muertes en más de 185 países $^{1,2}$. Sin embargo, seis meses después de su aparición aún se desconoce información relevante de este para poder combatirlo. En la búsqueda de un tratamiento para esta infección han resonado varios medicamentos como remdesivir, favipiravir, ivermectina e hidroxicloroquina por mencionar algunos, pero los estudios continúan para determinar cuál será el tratamiento indicado para estar un paso más cerca a detener esta infección ${ }^{3}$. Mientras esto se logra, actualmente se usan algunos medicamentos para tratar la sintomatología relacionada a la infección por COVID-19 como acetaminofeno, ibuprofeno, antitusivos, expectorantes y ácido acetilsalicílico (más conocido como aspirina o ASA $)^{4}$. Debido al pánico creciente por la pandemia y el temor a infectarse, se teme que esta información pueda ser usada por la población que desconoce el uso y precauciones de estos medicamentos al automedicarse como forma de prevención de la enfermedad. Por esto, es necesario resaltar y recordar el pasado, en especial, del último fármaco mencionado, la aspirina.

Actualmente, se están realizando 11 estudios que incluyen el uso de aspirina ya sea sola o combinada con ivermectina o dexametasona ${ }^{5}$. Según la Asociación Farmacéutica Canadiense, la dosis es de 325-650 mg en adultos y su uso en menores de 18 años no está recomendado. Los efectos adversos pueden causar malestar gastrointestinal y se debe evitar en pacientes con insuficiencia renal, enfermedad de úlcera péptica, insuficiencia cardíaca y asma sensible a $\mathrm{ASA}^{4}$. La aspirina, además, se relaciona con un síndrome que causa alteración de la conciencia, del ritmo respiratorio, del tono muscular y reflejos, fiebre, convulsiones y vómitos denominado síndrome de Reye, en honor a quien lo describió por primera vez en el año $1963^{6}$. También se asocia con una encefalopatía no inflamatoria inexplicable, aumento de la presión intracraneal, elevación de aspartato transaminasa, alanina transaminasa, niveles de amoníaco e infiltraciones de grasa hepática ${ }^{7}$. Se han sugerido posibles etiologías de este síndrome como una toxina intrínseca que causa alteraciones en el sistema mitocondrial, el metabolismo disfuncional de lípidos y amoníaco, una toxina extrínseca que altera la respuesta del paciente al pródromo bacteriano o viral y susceptibilidad genética. Sin embargo, la ingesta de aspirina ha sido el único agente que se ha demostrado relacionado con este síndrome durante la fase viral prodrómica en niños pequeños, un hallazgo que condujo a la emisión de una advertencia contra su administración a niños en $1980^{6}$. Desde entonces, la incidencia ha disminuido a menos de dos casos por año ${ }^{8-10}$. Se cree que los salicilatos desacoplan la fosforilación oxidativa y deterioran la función de la enzima mitocondrial, lo que perjudica la función hepática ${ }^{10}$, sin embargo, no se ha descrito una reacción causal ${ }^{11}$. En revisiones previas de la literatura científica, los niños que desarrollaron el síndrome de Reye recibieron salicilatos en dosis altas durante varios días antes. La presentación tras la ingestión de aspirina fue típicamente entre tres y cinco días. En estos informes, se utilizaron dosis de aspirina que iban desde menos de 45 hasta más de $70 \mathrm{mg} / \mathrm{kg}^{8}$.

En una revisión de 26 casos de síndrome de Reye relacionados con la ingestión de aspirina, entre 1973 y 1982 en Australia, donde Reye describió por primera vez su síndrome de encefalopatía y degeneración grasa del hígado, las edades oscilaron entre tres meses y siete años (mediana 22 meses) $^{8}$. Recientemente, se reportó un caso de un adulto que presentaba un síndrome coronario agudo y que tenía antecedentes de síndrome de Reye durante la infancia, por lo cual fue tratado con aspirina en dosis baja, resaltando que en edades más avanzadas, cuando es más probable tener problemas cardiovasculares, un paciente con este tipo de antecedente debe ser cuidadosamente tratado ${ }^{8}$.

En otro reporte, Wolfe y cols. describieron a una mujer de 20 años que desarrolló una hepatitis mientras estaba en terapia con aspirina en dosis altas, y en los días siguientes desarrolló anorexia, náuseas, malestar abdominal y niveles anormales de enzimas hepáticas. Tras la interrupción del fármaco, los síntomas y valores de laboratorio del paciente volvieron a la normalidad ${ }^{9}$. Existen informes que muestran resultados mixtos en niños y adultos con respecto al regreso del síndrome de Reye tras una reexposición a aspirina ${ }^{8}$.

Aunque la incidencia de este síndrome ha disminuido, en estos tiempos no debemos bajar la guardia o desconocer esta consecuencia por el uso discriminado de aspirina. Nos preocupa de sobremanera, la sobremedicación y automedicación que puede traer consigo una pandemia como es COVID-19 y su manifestación letal como un síndrome encefalopático. Recordemos que "aquel que no conoce su historia está condenado a repetirla".

Giancarlos Conde-Cardona ${ }^{1}$, Neyder Contreras-Puentes ${ }^{1}$ y Michelle Polo-Martínez ${ }^{1}$ ${ }^{I}$ Grupo de Investigación GINUMED. Facultad de Medicina. Corporación Universitaria Rafael Núñez. Colombia. 


\section{Referencias bibliográficas}

1.- $\quad$ Singhal T. A review of Coronavirus Disease-2019 (COVID-19). Indian J Pediatr 2020; 87: 281-6. doi:10.1007/ s12098-020-03263-6.

2.- World Health Organization. Coronavirus disease (COVID-19) Situation Report. Weekly Epidemiological Update Coronavirus disease 2019 (COVID-19) 21 September 2020. (Fecha de acceso: 25 de septiembre de 2020). Disponible en: https:/www.who.int/docs/defaultsource/coronaviruse/situation-reports/20200921-weekly-epiupdate-6.pdf?sfvrsn=d9cf9496 6 .

3.- $\quad$ Yung-Fang T, Chian-Shiu C, Aliaksandr AY, Yi-Ying L, Yung-Hung L, Yi-Tsung L, et al. A Review of SARS-CoV-2 and the ongoing clinical trials. Int J Mol Sci 2020; 21: 2657. doi:10.3390/ijms21072657.

4.- Canadian Pharmacists Association. Compendium of Therapeutic Choices. COVID-19. 2020 (Fecha de acceso: 13 de julio de 2020). Disponible en: https://www.pharmacists. ca/cpha-ca/assets/File/cpha-on-the-issues/COVID-19 Chapter-EN-FINAL.pdf.

5.- Clinical Trials. Fecha de acceso: 12 de junio de 2020. Disponible en: https://clinicaltrials.gov/ct2/results?term $=\% 2$ 2aspirina $\% 22+$ and $+\% 22+$ covid $19 \% 22$.
6.- Noor A, Gradidge E. A case of Reye syndrome caused by influenza A virus. Ochsner J 2018; 18: 425-7. doi: 10.31486/ toj.18.0098.

7.- Reye R D, Morgan G, Baral J. Encephalopathy and fatty degeneration of the viscera. A disease entity in childhood. Lancet 1963; 2: 749-52.

8.- Magrum B G, Pickworth K K. Aspirin rechallenge in an adult patient previously diagnosed with Reye syndrome. AJHP 2019; 77: 123-7. doi:10.1093/ajhp/zxz276.

9.- Wolfe J D, Metzger A L, Goldstein R C. Aspirin hepatitis. Ann Intern Med 1974; 80: 74-6

10.- Sullivan K M, Belay E D, Durbin R E, Foster D A, Nordenberg D F. Epidemiology of Reye's syndrome, United States, 1991-1994: comparison of CDC surveillance and hospital admission data. Neuroepidemiology 2000; 19: 33844. doi: 10.1159/000026274.

11.- Kirkpatrick D B, Ottoson C, Bateman LL. Reye's syndrome in an adult patient. West J Med 1986; 144: 223-5.

Correspondencia a: Michelle Polo Martínez mpolom10@curnvirtual.edu.co 